\title{
Hyperuricemia as a Protective Factor for Mild Cognitive Impairment in Non-Obese Elderly
}

\author{
Feng Wang, ${ }^{1}$ Minghui Zhao, ${ }^{1}$ Zhaoli Han, ${ }^{1}$ Dai Li, ${ }^{1}$ Shishuang Zhang, ${ }^{1}$ \\ Yongqiang Zhang, ${ }^{1}$ Xiaodong Kong, ${ }^{1}$ Ning Sun, ${ }^{1}$ Qiang Zhang ${ }^{1}$ and Ping Lei ${ }^{1}$ \\ ${ }^{1}$ Department of Geriatrics, Tianjin Medical University General Hospital, Tianjin Geriatrics Institute, Tianjin, \\ China
}

Mild cognitive impairment $(\mathrm{MCl})$ is regarded as incipient dementia. Patients with $\mathrm{MCl}$ have increased risk of later progressing to dementia. Blood uric acid (UA) is an important non-enzymatic antioxidant in peripheral circulation, and plays an unconfirmed protective role in $\mathrm{MCl}$. Furthermore, obesity-induced inflammation, which affects UA metabolism and $\mathrm{MCl}$ onset, might regulate such protective role. Thus, the aim of the study was to determine the relationship of $\mathrm{UA}$ to $\mathrm{MCl}$ and the potential effect from inflammation. The study consisted of $933 \mathrm{MCl}$ patients diagnosed by neuropsychological scales and 933 controls with normal cognitive function. All subjects were $\geq 60$ years old. There were 378 obese subjects in $\mathrm{MCl}$ group and 410 obese subjects in control group. A relationship between lower serum UA levels and higher risk of $\mathrm{MCl}$ was found in all $\mathrm{MCl}$ patients and non-obese $\mathrm{MCl}$ patients (OR: 0.78, 95\% Cl: $0.72 \sim 0.86$; OR: 0.66, $95 \% \mathrm{Cl}: 0.55 \sim 0.78$ ), but not in obese $\mathrm{MCl}$ patients (OR: 0.94, 95\% Cl: $0.81 \sim 1.12$ ). Serum UA and hypersensitive $\mathrm{C}$ reactive protein (hs-CRP) levels were higher in obese $\mathrm{MCl}$ patients than in non-obese $\mathrm{MCl}$ patients $(\mathrm{P}<0.001$ and $\mathrm{P}<0.001)$. Serum UA levels showed a positive linear correlation with serum hs-CRP levels in obese $\mathrm{MCl}$ patients $(r=0.284, \mathrm{P}<0.001)$, but not in non-obese $\mathrm{MCl}$ patients $(r=0.030, \mathrm{P}$ $=0.481)$. In conclusion, we show the significant association between lower serum UA levels and higher risk of $\mathrm{MCl}$ in non-obese subjects. Obesity-induced inflammation may weaken such relationship.

Keywords: hyperuricemia; inflammation; mild cognitive impairment; obesity; uric acid Tohoku J. Exp. Med., 2017 May, 242 (1), 37-42. C 2017 Tohoku University Medical Press

\section{Introduction}

Dementia is a class of geriatric diseases globally, and it includes Alzheimer's disease, vascular dementia, Lewy body dementia and so on (Beck et al. 1993). In recent years, dementia has become a non-negligible healthy problem. Nearly eight million elderly people are diagnosed with dementia annually in the world (Hayakawa et al. 2015). Furthermore, there is actually no effective treatment against dementia (Olsen et al. 2016). Many severe patients have a poor quality of life with no dignity. At present, mild cognitive impairment (MCI) is regarded as a transitional state before onset of dementia (Luchsinger et al. 2007). Therefore, people might stand a good chance of preventing the onset of dementia, if some timely and effective interventions could be conducted at this stage (Winblad et al. 2004).

Previous studies revealed that blood glucose regulation disorder and hyperlipemia contributed to increased risk of dementia in patients with type 2 diabetes mellitus (Yaffe et al. 2006; Kloppenborg et al. 2008; Whitmer et al. 2009). Several hypoglycemic and blood lipid lowering drugs, such as metformin and statins, had preventive and treatment effects on dementia in both epidemiological and animal studies (Risner et al. 2006; Li et al. 2012; Hendrie et al. 2015). Hyperuricemia is another metabolic disorder, and is closely related to metabolic syndrome (Sah et al. 2016). Thus, hyperuricemia might promote the development of MCI.

On the contrary, cognitive dysfunction is associated with the increase of reactive oxygen species (ROS) levels and the decrease of antioxidant levels (Fukui et al. 2002; Comin et al. 2010). Blood uric acid (UA), as well as albumin and total bilirubin, is an important non-enzymatic antioxidant in peripheral circulation, and might play a protective role in the development of MCI (Chen et al. 2016;

Received January 30, 2017; revised and accepted April 28, 2017. Published online May 19, 2017; doi: 10.1620/tjem.242.37.

Correspondence: Ping Lei, M.D., Ph.D., Department of Geriatrics, Tianjin Medical University General Hospital, Tianjin Geriatrics

Institute, No. 154, Anshan Road, Heping District, Tianjin 300052, China.

e-mail: leiping1974@163.com

Qiang Zhang, M.D., Ph.D., Department of Geriatrics, Tianjin Medical University General Hospital, Tianjin Geriatrics Institute, No. 154, Anshan Road, Heping District, Tianjin 300052, China.

e-mail: zhangqiangyulv@163.com 
Yang et al. 2016). Therefore, the relationship between serum UA levels and MCI risk is complicated and diverse, and a firm conclusion could not be drawn (Khan et al. 2016).

As we all know, obesity is a common adverse factor in human health. It induces chronic and subclinical inflammation (Dagdeviren et al. 2016). Hypersensitive $\mathrm{C}$ reactive protein (hs-CRP) is a proinflammatory marker, and its expression is upregulated in obese people (Mekala et al. 2016). Furthermore, this inflammation is implicated in the development of dementia, and also affects UA metabolism (Hermida et al. 2012; Enciu and Popescu 2013; Dal et al. 2015; Liu et al. 2016). Thus, obesity-induced chronic inflammation might be a confounding factor on the relationship between MCI and UA. But, such effect has not been well investigated.

Therefore, we conducted a study to reveal the relationship between serum UA levels and the risk of MCI in elderly people, and to further clarify the impact of obesityinduced chronic inflammation on such relationship.

\section{Materials and Methods}

\section{Participants}

A total of 933 patients with confirmed MCI were enrolled in the present study from Department of Geriatrics, Tianjin Medical University General Hospital between January 1, 2010 and August 31, 2016. Inclusion criteria were predefined as follows: (1) patients were $\geq 60$ years old; (2) patients were not diagnosed with Alzheimer's disease, vascular dementia, Lewy body dementia and other type of dementia; (3) Mini Mental State Examination (MMSE) and Montreal Cognitive Assessment (MoCA) revealed cognitive disorder. Diagnosis of MCI was determined by two psychologists.

The study also included 933 age- and sex-matched controls with normal cognitive function from Department of Medical Examination, Tianjin Medical University General Hospital in the same period. All patients and controls in the study did not suffer from acute coronary syndrome, heart failure, liver and kidney diseases, systemic autoimmune diseases, severe infections, malignancies and mental diseases. All patients and controls signed written informed consent forms. The present study was approved by the ethics committee of Tianjin Medical University General Hospital.

\section{Data collection}

Fasting blood specimen was collected from each subject for three times separately on admission, one month later and two months later. All specimens were centrifuged and separated. Serum levels of fibrinogen, triglyceride, total cholesterol, albumin, total bilirubin, hsCRP and UA were determined in biochemical laboratory in Tianjin Medical University General Hospital within 2 hours using a siemens ADVIA-2400 automatic biochemical analyzer (Erlangen, Germany). All three specimens of each subject were measured, and the mean was reported. Serum UA level $\geq 420 \mu \mathrm{mol} / \mathrm{L}$ and serum hs-CRP level $\geq 10 \mathrm{mg} / \mathrm{L}$ were considered abnormal, and the subjects were divided into several groups according to $420 \mu \mathrm{mol} / \mathrm{L}$ of UA and $10 \mathrm{mg} / \mathrm{L}$ of hs-CRP in the study.

All subjects received medical examinations and face to face interviews. Demographic information, education level, medical history, treatment history and other useful information were obtained.
Body mass index (BMI) was calculated using a formula: BMI $\left(\mathrm{kg} / \mathrm{m}^{2}\right)$ $=$ weight $(\mathrm{kg}) /$ height $^{2}\left(\mathrm{~m}^{2}\right)$. Obesity was defined as BMI $\geq 30 \mathrm{~kg} / \mathrm{m}^{2}$ according to World Health Organization (WHO) criteria, and nonobesity was defined as BMI $<30 \mathrm{~kg} / \mathrm{m}^{2}$ (WHO 2000).

In MMSE, full mark was 30 points. Subjects with $<20$ points and $<24$ points were considered to be cognitive disorder separately in subjects with primary school education and more than primary school education. In MoCA, full mark was still 30 points. Subjects with $<$ 25 points and $<26$ points were considered to be cognitive disorder separately in subjects with $\leq 12$ years education and $>12$ years education (Molloy and Standish 1997; Olson et al. 2008).

\section{Statistical analysis}

In the present study, Statistical Product and Service Solution (SPSS) version 19.0 (Chicago, IL, USA) was adopted for statistical analysis. Continuous variable was showed by mean \pm standard deviation (SD), and categorical variable was expressed as frequency. Difference of continuous variables was determined by independent sample $t$ test, and difference of categorical variables was detected by chi-square test. Connection between serum level of UA and serum level of hs-CRP was determined by Pearson correlation analysis. If a $P$ value was less than 0.05 , it was regarded as statistical significance. Association of MCI risk with serum levels of UA and hs-CRP was assessed using multivariate logistic regression analysis. Odds ratio (OR) and 95\% confidence interval (CI) were reported in the study. If a $95 \% \mathrm{CI}$ did not include value one, it was regarded as statistical significance.

\section{Results}

As shown in Table 1, 933 MCI patients and 933 controls were included in the study. Systolic pressure, diastolic pressure, serum levels of fibrinogen, triglyceride, total cholesterol and hs-CRP were significantly higher in MCI patients than those in controls $(\mathrm{P}<0.001, \mathrm{P}<0.001, \mathrm{P}<$ $0.001, \mathrm{P}<0.001, \mathrm{P}<0.001$ and $\mathrm{P}=0.021$, respectively). Onset of diabetes mellitus was more common in MCI patients than that in controls $(\mathrm{P}<0.001)$. Serum levels of UA were significantly lower in MCI patients compared with the levels in controls $(\mathrm{P}<0.001)$. In addition, there were no significant differences in sex, age, BMI and onset of stable angina pectoris between MCI patients and controls $(\mathrm{P}=$ $0.071, P=0.100, P=0.469$ and $P=0.224)$. Serum levels of albumin and total bilirubin were also equivalent between MCI patients and controls $(\mathrm{P}=0.101$ and $\mathrm{P}=0.172)$.

There were 378 obese subjects in MCI group and 410 obese subjects in control group. As shown in Table 2, multivariate logistic regression analysis reported significant associations between higher serum UA levels and lower risk of MCI in all MCI patients and non-obese MCI patients (OR: $0.78,95 \%$ CI: $0.72 \sim 0.86$ and OR: $0.66,95 \%$ CI: $0.55 \sim 0.78)$. In obese MCI patients, the potential association between serum UA levels and MCI risk was not found (OR: 0.94, 95\% CI: $0.81 \sim 1.12$ ).

As shown in Table 3, higher risk of MCI was also related to higher serum levels of hs-CRP in all MCI patients and obese MCI patients (OR: 2.41, 95\% CI: $1.85 \sim 2.99$ and OR: $4.37,95 \%$ CI: $3.08 \sim 5.94)$, but not in non-obese 
Table 1. Characteristics of mild cognitive impairment patients and controls in the study.

\begin{tabular}{lccc}
\hline & MCI & Control & P value $^{\mathrm{b}}$ \\
\hline Total $(\mathrm{n})^{\mathrm{a}}$ & 933 & 933 & - \\
Male $(\mathrm{n})$ & 492 & 453 & 0.071 \\
Age $($ years) & $74.7 \pm 9.3$ & $75.4 \pm 8.8$ & 0.100 \\
BMI $\left(\mathrm{kg} / \mathrm{m}^{2}\right)$ & $26.8 \pm 4.1$ & $26.6 \pm 3.2$ & 0.469 \\
Systolic pressure $(\mathrm{mmHg})$ & $147.3 \pm 19.8$ & $143.3 \pm 20.7$ & $<0.001$ \\
Diastolic pressure $(\mathrm{mmHg})$ & $77.2 \pm 12.1$ & $74.3 \pm 11.1$ & $<0.001$ \\
Fibrinogen $(\mathrm{g} / \mathrm{L})$ & $2.9 \pm 0.6$ & $2.8 \pm 0.6$ & $<0.001$ \\
Triglyceride $(\mathrm{mmol} / \mathrm{L})$ & $1.8 \pm 1.3$ & $1.5 \pm 1.0$ & $<0.001$ \\
Total cholesterol $(\mathrm{mmol} / \mathrm{L})$ & $5.2 \pm 1.0$ & $5.0 \pm 1.0$ & $<0.001$ \\
Albumin $(\mathrm{g} / \mathrm{L})$ & $45.8 \pm 2.7$ & $45.6 \pm 2.7$ & 0.101 \\
Total bilirubin $(\mu \mathrm{mol} / \mathrm{L})$ & $13.9 \pm 5.8$ & $13.6 \pm 5.3$ & 0.172 \\
hs-CRP $(\mathrm{mg} / \mathrm{L})$ & $8.6 \pm 3.0$ & $8.1 \pm 5.6$ & 0.021 \\
Uric acid $(\mu \mathrm{mol} / \mathrm{L})$ & $352.4 \pm 81.2$ & $382.3 \pm 98.5$ & $<0.001$ \\
Stable angina pectoris $(\mathrm{n})$ & 201 & 223 & 0.224 \\
Diabetes mellitus $(\mathrm{n})$ & 369 & 234 & $<0.001$ \\
\hline
\end{tabular}

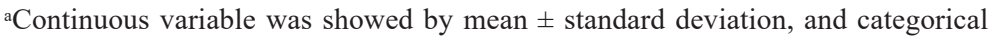
variable was expressed as frequency.

bifference of continuous variables was determined by independent sample $t$ test, and Difference of categorical variables was detected by chi-square test. If a $\mathrm{P}$ value was less than 0.05 , it was regarded as statistical significance.

BMI, Body mass index; MCI, Mild cognitive impairment; hs-CRP, Hypersensitive $\mathrm{C}$ reactive protein.

Table 2. Association between serum level of uric acid and onset of mild cognitive impairment according to obesity.

\begin{tabular}{|c|c|c|c|c|}
\hline $\begin{array}{c}\text { Serum level of UA } \\
(\mu \mathrm{mol} / \mathrm{L})\end{array}$ & $\begin{array}{l}\mathrm{MCI} \\
(\mathrm{n})\end{array}$ & $\begin{array}{l}\text { Control } \\
\text { (n) }\end{array}$ & $\begin{array}{l}\text { Age and gender adjusted } \\
\text { OR }(95 \% \mathrm{CI})^{\mathrm{a}}\end{array}$ & $\begin{array}{l}\text { Multivariable adjusted } \\
\text { OR }(95 \% \mathrm{CI})^{\mathrm{a}}\end{array}$ \\
\hline \multicolumn{5}{|l|}{ Total } \\
\hline$<420$ & 545 & 423 & Reference & Reference \\
\hline$\geqslant 420$ & 388 & 510 & $0.77(0.70 \sim 0.84)$ & $0.78(0.72 \sim 0.86)$ \\
\hline \multicolumn{5}{|l|}{ Non-obesity } \\
\hline$<420$ & 440 & 321 & Reference & Reference \\
\hline$\geqslant 420$ & 115 & 202 & $0.63(0.54 \sim 0.73)$ & $0.66(0.55 \sim 0.78)$ \\
\hline \multicolumn{5}{|l|}{ Obesity } \\
\hline$<420$ & 105 & 102 & Reference & Reference \\
\hline$\geqslant 420$ & 273 & 308 & $0.93(0.79 \sim 1.09)$ & $0.94(0.81 \sim 1.12)$ \\
\hline
\end{tabular}

${ }^{a}$ Age and gender adjusted odds ratio was adjusted for age and gender. Multivariable adjusted odds ratio was adjusted for age, gender, race, blood pressure, onset of stable angina pectoris and diabetes mellitus, serum levels of fibrinogen, triglyceride, total cholesterol, albumin, total bilirubin and hypersensitive $\mathrm{C}$ reactive protein. If a $95 \%$ confidence interval did not include value one, it was regarded as statistical significance. UA, Uric acid; MCI, Mild cognitive impairment; OR, Odds ratio; CI, Confidence interval.

patients (OR: 1.27, 95\% CI: $0.89 \sim 1.95$ ).

As shown in Table 4, there were 378 obese MCI patients and 555 non-obese MCI patients in the study. The study revealed that systolic pressure, diastolic pressure, serum levels of fibrinogen, triglyceride, total cholesterol, hs-CRP and UA were higher in obese MCI patients than those in non-obese $\mathrm{MCI}$ patients $(\mathrm{P}<0.001, \mathrm{P}<0.001, \mathrm{P}<$ 0.001, $\mathrm{P}<0.001, \mathrm{P}<0.001, \mathrm{P}<0.001$ and $\mathrm{P}<0.001$ ). However, no such difference was found in serum levels of albumin and total bilirubin $(\mathrm{P}=0.457$ and $\mathrm{P}=0.465)$.

As shown in Fig. 1, serum levels of UA showed a posi- tive linear correlation with serum levels of hs-CRP in obese MCI patients $(\mathrm{r}=0.284, \mathrm{P}<0.001)$, but not in non-obese MCI patients $(\mathrm{r}=0.030, \mathrm{P}=0.481)$. In addition, serum UA levels showed no such linear correlation both in obese MCI patients and in non-obese MCI patients with systolic pressure $(\mathrm{r}=0.046, \mathrm{P}=0.605$ and $\mathrm{r}=0.145, \mathrm{P}=0.051)$, diastolic pressure $(\mathrm{r}=0.041, \mathrm{P}=0.646$ and $\mathrm{r}=0.024, \mathrm{P}=$ $0.744)$, serum levels of fibrinogen $(r=0.048, P=0.595$ and $\mathrm{r}=0.005, \mathrm{P}=0.945)$, triglyceride $(\mathrm{r}=0.125, \mathrm{P}=0.164$ and $\mathrm{r}=0.065, \mathrm{P}=0.378)$ and total cholesterol $(\mathrm{r}=0.165, \mathrm{P}=$ 0.065 and $\mathrm{r}=0.042, \mathrm{P}=0.574$ ). 
Table 3. Association between serum level of hypersensitive $\mathrm{C}$ reactive protein and onset of mild cognitive impairment according to obesity.

\begin{tabular}{lcccc}
\hline $\begin{array}{c}\text { Serum level of hs-CRP } \\
(\mathrm{mg} / \mathrm{L})\end{array}$ & $\begin{array}{c}\text { MCI } \\
(\mathrm{n})\end{array}$ & $\begin{array}{c}\text { Control } \\
(\mathrm{n})\end{array}$ & $\begin{array}{c}\text { Age and gender adjusted } \\
\text { OR }(95 \% \mathrm{CI})^{\mathrm{a}}\end{array}$ & $\begin{array}{c}\text { Multivariable adjusted } \\
\text { OR }(95 \% \mathrm{CI})^{\mathrm{a}}\end{array}$ \\
\hline $\begin{array}{c}\text { Total } \\
<10\end{array}$ & 690 & 807 & Reference & Reference \\
$\quad \geqslant 10$ & 243 & 126 & $2.26(1.78 \sim 2.86)$ & $2.41(1.85 \sim 2.99)$ \\
$\begin{array}{c}\text { Non-obesity } \\
<10\end{array}$ & 486 & 467 & Reference & Reference \\
$\geqslant 10$ & 69 & 56 & $1.18(0.81 \sim 1.72)$ & $1.27(0.89 \sim 1.95)$ \\
$\begin{array}{l}\text { Obesity } \\
<10\end{array}$ & 204 & 340 & Reference & Reference \\
$\geqslant 10$ & 174 & 70 & $4.14(2.97 \sim 5.75)$ & $4.37(3.08 \sim 5.94)$ \\
\hline
\end{tabular}

${ }^{a}$ Age and gender adjusted odds ratio was adjusted for age and gender. Multivariable adjusted odds ratio was adjusted for age, gender, race, blood pressure, onset of stable angina pectoris and diabetes mellitus, serum levels of fibrinogen, triglyceride, total cholesterol, albumin, total bilirubin and uric acid. If a $95 \%$ confidence interval did not include value one, it was regarded as statistical significance.

hs-CRP, Hypersensitive $\mathrm{C}$ reactive protein; $\mathrm{MCI}$, Mild cognitive impairment; OR, Odds ratio; CI, Confidence interval.

Table 4. Characteristics of mild cognitive impairment patients according to obesity.

\begin{tabular}{lccc}
\hline & Obesity & Non-obesity & P value $^{\text {b }}$ \\
\hline${\text { Total }(\mathrm{n})^{\mathrm{a}}}$ & 378 & 555 & - \\
Systolic pressure $(\mathrm{mmHg})$ & $151.6 \pm 20.0$ & $144.3 \pm 19.2$ & $<0.001$ \\
Diastolic pressure $(\mathrm{mmHg})$ & $79.4 \pm 12.4$ & $75.7 \pm 11.7$ & $<0.001$ \\
Fibrinogen $(\mathrm{g} / \mathrm{L})$ & $3.1 \pm 0.6$ & $2.9 \pm 0.5$ & $<0.001$ \\
Triglyceride $(\mathrm{mmol} / \mathrm{L})$ & $2.0 \pm 1.3$ & $1.7 \pm 1.4$ & $<0.001$ \\
Total cholesterol $(\mathrm{mmol} / \mathrm{L})$ & $5.4 \pm 0.8$ & $5.0 \pm 1.0$ & $<0.001$ \\
Albumin $(\mathrm{g} / \mathrm{L})$ & $45.9 \pm 3.0$ & $45.8 \pm 2.4$ & 0.457 \\
Total bilirubin $(\mu \mathrm{mol} / \mathrm{L})$ & $14.1 \pm 7.5$ & $13.8 \pm 4.3$ & 0.465 \\
hs-CRP $(\mathrm{mg} / \mathrm{L})$ & $10.7 \pm 2.5$ & $7.2 \pm 2.5$ & $<0.001$ \\
Uric acid $(\mu \mathrm{mol} / \mathrm{L})$ & $415.2 \pm 123.6$ & $332.2 \pm 64.4$ & $<0.001$ \\
\hline
\end{tabular}

${ }^{a}$ Continuous variable was showed by mean \pm standard deviation, and categorical variable was expressed as frequency.

${ }^{b}$ Difference of continuous variables was determined by independent sample $t$ test, and Difference of categorical variables was detected by chi-square test. If a $P$ value was less than 0.05 , it was regarded as statistical significance. hs-CRP, Hypersensitive $\mathrm{C}$ reactive protein.

\section{Discussion}

A previous published meta-analysis focused on the relationship between serum level of UA and cognitive impairment, but had not given us a conclusion we needed. (Khan et al. 2016). In the present study, we showed a more than $30 \%$ decreased risk of $\mathrm{MCI}$ in non-obese subjects with serum UA levels of $\geq 420 \mu \mathrm{mol} / \mathrm{L}$. But, the study did not find any differences in serum levels of albumin and total bilirubin among obese MCI patients, non-obese MCI patients and controls. As we all know, UA, albumin and total bilirubin were three major non-enzymatic antioxidants in peripheral circulation. Therefore, antioxidative activities might not fully explain the protective effect of UA on MCI risk.

As mentioned above, obesity and its chronic subclinical inflammation are related to cognitive impairment and
UA metabolism (Duan et al. 2015; Pedditizi et al. 2016). A subgroup analysis was conducted according to obesity. Then, the relationship between serum level of UA and MCI risk was disappeared in obese MCI patients.

There are three other findings in the present study. First, serum hs-CRP levels were remarkably higher in obese MCI patients compared with non-obese MCI patients. Second, higher serum levels of hs-CRP were associated with higher risk of $\mathrm{MCI}$ in obese subjects, but not in nonobese subjects. Third, serum levels of hs-CRP and UA showed a linear correlation in obese MCI patients, but not in non-obese MCI patients. Taken together, a following speculation seems to be reasonable. Obesity-induced chronic inflammation might attenuate potential relationship between serum UA levels and MCI risk in elderly people.

Adipose tissues release many adipocytokines, which can regulate memory and cognition. A previous study 

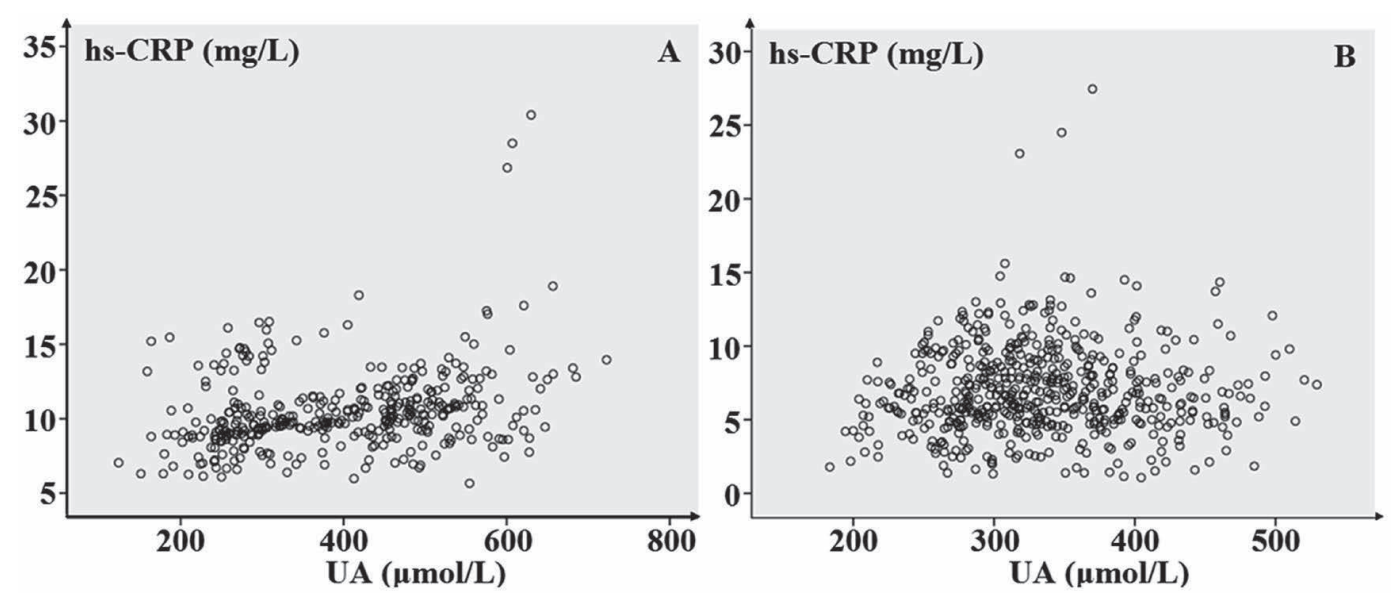

Fig. 1. Correlation of serum uric acid and hypersensitive $\mathrm{C}$ reactive protein levels according to obesity.

Pearson correlation analysis was adopted. If a $\mathrm{P}$ value $<0.05$, it was considered to be significant. hs-CRP, Hypersensitive $\mathrm{C}$ reactive protein; $\mathrm{UA}$, Uric acid.

A: Serum levels of UA show a positive linear correlation with serum levels of hs-CRP in obese patients with mild cognitive impairment $(\mathrm{r}=0.284, \mathrm{P}<0.001)$. The number of subjects was 378 .

B: Serum levels of UA show no linear correlation with serum levels of hs-CRP in non-obese patients with mild cognitive impairment $(r=0.030, P=0.481)$. The number of subjects was 555 .

revealed that serum and cerebrospinal fluid levels of adiponectin (one of the most important adipocytokines) were increased in the patients with MCI and Alzheimer's disease (Une et al. 2011). Thus, effect of obesity on the relationship between serum level of UA and MCI risk might be related to other mechanisms (e.g., adipocytokines). More researches are needed to reveal these mechanisms.

Previous studies also revealed that several vascular factors, such as blood pressure, fibrinogen and blood fat, were associated with cognitive dysfunction (Eftekhari et al. 2007; Xu et al. 2008; Panza et al. 2009). In the present study, these factors were significantly higher in obese MCI patients compared to non-obese MCI patients. So, they should be confounding factors. But multivariate logistic regression analysis in the study had adjusted for such factors, and further analysis did not report a linear correlation between UA and these factors. Therefore, vascular disorder might not affect the relationship between serum level of UA and MCI risk.

In the study, WHO criteria was adopted, and BMI $\geq 30$ $\mathrm{kg} / \mathrm{m}^{2}$ was defined as obesity (WHO 2000). Strictly speaking, people with $\mathrm{BMI} \geq 30 \mathrm{~kg} / \mathrm{m}^{2}$ should not be regarded as obesity directly. Because density of muscle was larger than that of fat, people with more muscle showed higher level of BMI. However, we did not think it changed our conclusion, because only elderly people (more than 60 years old) were included in the study. Many serological indicators (e.g., UA) were not stable. The study conducted multiple blood sample collection for each subject. Arithmetical mean was adopted in the analysis. This arrangement might avoid potential bias.

In conclusion, there is a significant association between lower serum levels of UA and higher risk of MCI especially in non-obese people. Obesity-induced chronic and subclinical inflammation might weaken such relationship.

\section{Acknowledgments}

This project is supported by the National Clinical Key Subject Construction Project of NHFPC Fund.

This project is supported by the National Natural Science Fund $(81471252,81670086)$.

\section{Conflict of Interest}

The authors declare no conflict of interest.

\section{References}

Beck, C.K., Heacock, P., Rapp, C.G. \& Shue, V. (1993) Cognitive impairment in the elderly. Nurs. Clin. North. Am., 28, 335-347.

Chen, Z., Su, Z., Pang, W., Huang, Y., Lin, J., Ding, Z., Wu, S., Xu, S., Quan, W., Zheng, J., Chen, H., Li, Z., Li, X., Li, J., Weng, Y. \& Zhang, X. (2016) Antioxidant status of serum bilirubin and uric acid in patients with polymyositis and dermatomyositis. Int. J. Neurosci., 127, 617-623.

Comin, D., Gazarini, L., Zanoni, J.N., Milani, H. \& de Oliveira, R.M. (2010) Vitamin E improves learning performance and changes the expression of nitric oxide-producing neurons in the brains of diabetic rats. Behav. Brain Res., 210, 38-45.

Dagdeviren, S., Jung, D.Y., Lee, E., Friedline, R.H., Noh, H.L., Kim, J.H., Patel, P.R., Tsitsilianos, N., Tsitsilianos, A.V., Tran, D.A., Tsougranis, G.H., Kearns, C.C., Uong, C.P., Kwon, J.Y., Muller, W., Lee, K.W. \& Kim, J.K. (2016) Altered Interleukin-10 Signaling in Skeletal Muscle Regulates ObesityMediated Inflammation and Insulin Resistance. Mol. Cell. Biol., 36, 2956-2966.

Dal, M.S., Karakus, A., Aydin, B.B., Ekmen, M.O., Ulas, T. \& Ayyildiz, O. (2015) Serum uric acid and inflammation in patients with immune thrombocytopenic purpura: preliminary results. Eur. Rev. Med. Pharmacol. Sci., 19, 4385-4389.

Duan, Y., Liang, W., Zhu, L., Zhang, T., Wang, L., Nie, Z., Chen, Y., He, L., Jin, Y. \& Yao, Y. (2015) Association between serum uric acid levels and obesity among university students 
(China). Nutr. Hosp., 31, 2407-2411.

Eftekhari, H., Uretsky, S. \& Messerli, F.H. (2007) Blood pressure, cognitive dysfunction, and dementia. J. Am. Soc. Hypertens., 1, 135-144.

Enciu, A.M. \& Popescu, B.O. (2013) Is there a causal link between inflammation and dementia? Biomed. Res. Int., 2013, 316495 .

Fukui, K., Omoi, N.O., Hayasaka, T., Shinnkai, T., Suzuki, S., Abe, K. \& Urano, S. (2002) Cognitive impairment of rats caused by oxidative stress and aging, and its prevention by vitamin $\mathrm{E}$. Ann. NY Acad. Sci., 959, 275-284.

Hayakawa, T., McGarrigle, C.A., Coen, R.F., Soraghan, C.J., Foran, T., Lawlor, B.A. \& Kenny, R.A. (2015) Orthostatic Blood Pressure Behavior in People with Mild Cognitive Impairment Predicts Conversion to Dementia. J. Am. Geriatr. Soc., 63, 1868-1873.

Hendrie, H.C., Hake, A., Lane, K., Purnell, C., Unverzagt, F., Smith-Gamble, V., Murrell, J., Ogunniyi, A., Baiyewu, O., Callahan, C., Saykin, A., Taylor, S., Hall, K. \& Gao, S. (2015) Statin Use, Incident Dementia and Alzheimer Disease in Elderly African Americans. Ethn. Dis., 25, 345-354.

Hermida, A.P., McDonald, W.M., Steenland, K. \& Levey, A. (2012) The association between late-life depression, mild cognitive impairment and dementia: is inflammation the missing link? Expert Rev. Neurother., 12, 1339-1350.

Khan, A.A., Quinn, T.J., Hewitt, J., Fan, Y. \& Dawson, J. (2016) Serum uric acid level and association with cognitive impairment and dementia: systematic review and meta-analysis. Age (Dordr.), 38, 16.

Kloppenborg, R.P., van den Berg, E., Kappelle, L.J. \& Biessels, G.J. (2008) Diabetes and other vascular risk factors for dementia: which factor matters most? A systematic review. Eur. J. Pharmacol., 585, 97-108.

Li, J., Deng, J., Sheng, W. \& Zuo, Z. (2012) Metformin attenuates Alzheimer's disease-like neuropathology in obese, leptinresistant mice. Pharmacol. Biochem. Behav., 101, 564-574.

Liu, J., Xu, C., Ying, L., Zang, S., Zhuang, Z., Lv, H., Yang, W., Luo, Y., Ma, X., Wang, L., Xun, Y., Ye, D. \& Shi, J. (2016) Relationship of serum uric acid level with non-alcoholic fatty liver disease and its inflammation progression in non-obese adults. Hepatol. Res., 47, E104-E112.

Luchsinger, J.A., Reitz, C., Patel, B., Tang, M.X., Manly, J.J. \& Mayeux, R. (2007) Relation of diabetes to mild cognitive impairment. Arch. Neurol., 64, 570-575.

Mekala, A., Murthy, S.V., Prasuna, K.S. \& Chinta, V.A. (2016) Study of C-reactive protein levels in overweight and obese individuals in comparison to healthy subjects. J. Assoc. Physicians India, 64, 46.

Molloy, D.W. \& Standish, T.I. (1997) A guide to the standardized Mini-Mental State Examination. Int. Psychogeriatr., 9 (S1), 87-94.

Olsen, C., Pedersen, I., Bergland, A., Enders-Slegers, M.J., Jøranson, N., Calogiuri, G. \& Ihlebæk, C. (2016) Differences in quality of life in home-dwelling persons and nursing home residents with dementia - a cross-sectional study. $B M C$ Geriatr., 16, 137.

Olson, R.A., Chhanabhai, T. \& McKenzie, M. (2008) Feasibility study of the Montreal Cognitive Assessment (MoCA) in patients with brain metastases. Support. Care Cancer, 16, 1273-1278.

Panza, F., Solfrizzi, V., D’Introno, A., Colacicco, A.M., Santamato, A., Seripa, D., Pilotto, A., Capurso, A. \& Capurso, C. (2009) Higher total cholesterol, cognitive decline, and dementia. Neurobiol. Aging, 30, 546-548.

Pedditizi, E., Peters, R. \& Beckett, N. (2016) The risk of overweight/obesity in mid-life and late life for the development of dementia: a systematic review and meta-analysis of longitudinal studies. Age Ageing, 45, 14-21.

Risner, M.E., Saunders, A.M., Altman, J.F., Ormandy, G.C., Craft, S., Foley, I.M., Zvartau-Hind, M.E., Hosford, D.A. \& Roses, A.D. (2006) Efficacy of rosiglitazone in a genetically defined population with mild-to-moderate Alzheimer's disease. Pharmacogenomics J., 6, 246-254.

Sah, S.K., Khatiwada, S., Pandey, S., Kc, R., Das, B.K., Baral, N. \& Lamsal, M. (2016) Association of high-sensitivity C-reactive protein and uric acid with the metabolic syndrome components. Springerplus, 5, 269.

Une, K., Takei, Y.A., Tomita, N., Asamura, T., Ohrui, T., Furukawa, K. \& Arai, H. (2011) Adiponectin in plasma and cerebrospinal fluid in MCI and Alzheimer's disease. Eur. J. Neurol., 18, 1006-1009.

Whitmer, R.A., Karter, A.J., Yaffe, K., Quesenberry, C.P. Jr. \& Selby, J.V. (2009) Hypoglycemic episodes and risk of dementia in older patients with type 2 diabetes mellitus. JAMA, 301, 1565-1572.

Winblad, B., Palmer, K., Kivipelto, M., Jelic, V., Fratiglioni, L., Wahlund, L.O., Nordberg, A., Bäckman, L., Albert, M., Almkvist, O., Arai, H., Basun, H., Blennow, K., de Leon, M., DeCarli, C., et al. (2004) Mild cognitive impairment—beyond controversies, towards a consensus: report of the International Working Group on Mild Cognitive Impairment. J. Intern. Med., 256, 240-246.

World Health Organization (WHO) (2000) Obesity: preventing and managing the global epidemic: report of a WHO consultation. World Health Organ. Tech. Rep. Ser, 894, i-xii, 1-253.

Xu, G., Zhang, H., Zhang, S., Fan, X. \& Liu, X. (2008) Plasma fibrinogen is associated with cognitive decline and risk for dementia in patients with mild cognitive impairment. Int. $J$. Clin. Pract., 62, 1070-1075.

Yaffe, K., Blackwell, T., Whitmer, R.A., Krueger, K. \& Barrett Connor, E. (2006) Glycosylated hemoglobin level and development of mild cognitive impairment or dementia in older women. J. Nutr. Health Aging, 10, 293-295.

Yang, D., Su, Z., Wu, S., Bi, Y., Li, X., Li, J., Lou, K., Zhang, H. \& Zhang, X. (2016) Low antioxidant status of serum bilirubin, uric acid, albumin and creatinine in patients with myasthenia gravis. Int. J. Neurosci., 126, 1120-1126. 